\title{
Inovação, Recursos e Comprometimento: em Direção a uma Teoria Estratégica da Firma
}

\author{
Leonardo Burlamaqui \\ UCAM e Faculdade de Ciências Econômicas/UERJ \\ Adriano Proença \\ EE-COPPE/UFRJ
}

ResUMO

$\mathrm{O}$ artigo se insere no esforço, atualmente em curso, de articulação conceitual entre as teorias da concorrência e da inovação forjadas pela teoria econômica Evolucionária e a teoria da firma desenvolvida pela Visão Baseada em Recursos (VBR) na área de gestão estratégica. Ele o faz em três planos: (i) sublinhando a convergência e complementaridade entre as proposições centrais da teoria econômica Evolucionária e a da VBR; (ii) trazendo à luz uma segunda convergência: da relação entre decisões empresariais sob incerteza e seu impacto econômico, associadas à perspectiva pós-keynesiana; (iii) mostrando como os modelos de processos de formação e gestão de estratégias empresariais vêm oferecendo proposições úteis, coerentes e complementares com este mesmo quadro conceitual.

A proposição fundamental do artigo é que a referida articulação aponta para uma teoria estratégica da firma centrada nas relaçôes entre concorrência, inovação, competitividade, decisões sob incerteza, comprometimento e busca de liquidez.

Palavras-Chave | Economia Evolucionária; Visão Baseada em Recursos; Capacidades Dinâmicas; Processo Estratégico; Gestão de Estratégias sob Incerteza Códigos JEL | B5, M2, L1, L2, D84 


\section{ABSTRACT}

This article intends to contribute with the ongoing effort towards a conceptual articulation among the theories of competition and innovation developed under the research program of Evolutionary Economics, the Resource-Based View in Strategic Management and the Post-Keynesian perspective on commitments and decision-making under uncertainty. It makes three main points: (i) it underlines the convergence and complementarities of the central propositions of Evolutionary Economics and the Resource-Based View; (ii) it brings out the convergence between the economics of uncertainty developed by the post-Keynesian research program and the commitment-capabilities approach pioneered by Penrose, Ghemawat, Teece and Pisano; (iii) it suggests that contemporary models of the strategy-making processes and strategic management are developing propositions that should be absorbed by this same conceptual framework.

The article thus concludes for the feasibility and usefulness for developing a Strategic Theory of the Firm grounded in the relationships among competition, innovation, competitiveness, decision-making under uncertainty, the inevitability of strategic commitments and the search for strategic liquidity.

KeYwords | Evolutionary Economics; Resource-Based View; Dynamic Capabilities; Strategy Process; Strategy-making under Uncertainty

JEL-CoDES $\quad$ B5, M2, L1, L2, D84

\section{Introdução}

A evolução da literatura em Gestão Estratégica vem se constituindo em uma importante fonte de questionamento do modelo de empresa difundido pela teoria econômica Neoclássica. A teoria econômica Evolucionária, por sua vez, vem buscando, especialmente nas discussões oriundas da chamada "Visão Baseada em Recursos" (VBR), adensar o seu programa de pesquisa, de modo a construir uma teoria da firma mais próxima, e mais útil, à realidade empresarial.

O presente texto pretende se inserir nesse debate de três formas: 
(a) sublinhando a convergência e complementaridade entre as proposições centrais da teoria econômica Evolucionária e da VBR;

(b) trazendo à luz uma segunda convergência: da relação entre decisões empresariais sob incerteza e seu impacto econômico, associados à perspectiva pós-keynesiana, e consistentes tanto com a teoria econômica Evolucionária quanto com a VBR, no que diz respeito ao comprometimento estratégico inerente ao processo de dotação, engajamento e acionamento coordenado de ativos tangíveis e intangíveis;

(c) mostrando como os modelos de processos de formação e gestão de estratégias empresariais vêm oferecendo proposições úteis, coerentes e complementares com este mesmo quadro conceitual de orientação evolucionária e pós-keynesiana.

Visto por um outro prisma, tal esforço de organização conceitual pode ser enquadrado em um contexto menos abstrato. Uma questão compulsória para estudiosos da economia capitalista refere-se a o que uma teoria dos comportamentos empresariais teria a dizer sobre as atuais mudanças na estrutura e nas formas de operação das empresas e das cadeias produtivas. Em última instância, trata-se de perguntar qual a orientação que a teoria econômica pode oferecer àqueles que tomam decisões que dependem de uma compreensão das referidas mudanças, e cujo impacto afeta seu curso futuro - empresários, gerentes e policymakers. Isto é, do ponto de vista da teoria econômica, e tendo como pano de fundo as novas realidades desta virada de século, trata-se de estabelecer qual a moldura conceitual mais adequada à interpretação dos processos em curso, do ponto de vista do balizamento à formulação de estratégias e políticas.

Nas páginas que se seguem, não se pretende — obviamente — dar "respostas definitivas” a essas questôes. Há várias possíveis. Nossa intenção é, todavia, indicar aquele que nos parece o caminho mais promissor para pensar sobre as mesmas. Trata-se de seguir uma linha de reflexão no âmbito da qual seja possível estabelecer um diálogo entre a teoria econômica e a de constituição e formação de estratégias empresariais, indicando como estas podem se "fertilizar reciprocamente".

A perspectiva analítica que vamos adotar para tal é a da teoria econômica

1 Exercícios anteriores neste sentido foram apresentados em Burlamaqui \& Proença (1997 e 2000). 
Evolucionária, que assume que o capitalismo é um processo histórico, e portanto dinâmico, onde a mudança, e não a estabilidade, é o fato mais relevante, e mais carente de investigação. Esse pressuposto é, como se verá, um "denominador comum", sobre o qual é possível articular as idéias de diversos autores e escolas.

Essa mesma perspectiva, por outro lado, restringe drasticamente, a nosso juízo, as possibilidades de utilização da teoria econômica convencional (o mainstream) como ponto de partida para a nossa reflexão, na medida em que no seu núcleo estão justamente os pressupostos da estabilidade, e da "tendência ao equilíbrio" como características fundamentais do objeto a ser analisado (cf. a esse respeito as observações contidas em Nelson \&Winter, 1982, caps. 2 e 6; Loasby, 1991; Magnusson, org., 1994; Rumelt et al., org., 1995).

Vamos apresentar, e tentar fundamentar, a sugestão de que há, no âmbito dessa preocupação com a dinâmica histórico-institucional e com processos de transformação, conceitos fundamentais que não os originados dos modelos de equilíbrio geral, que nos oferecem uma ampla gama de possibilidades ${ }^{2}$ de articulação com as teorias e proposições em estratégia empresarial. Sobretudo, como já dito, com a VBR, particularmente em suas considerações sobre o dinamismo das capacitações organizacionais e sobre o "comprometimento estratégico" inerente à construção de posiçōes competitivas defensáveis no tempo.

Nossa intenção nesse texto é indicar os fundamentos da proposição acima referida, tendo por horizonte a construção de uma "teoria estratégica da firma", que informe e organize a reflexão sobre a formação de estratégias bem-sucedidas no interior das organizações empresariais. Vale observar ainda que o escopo do texto se restringe à elaboração de uma primeira síntese conceitual, centrada na empresa em si. Não trataremos aqui da questão de sua aplicação em situações concretas, nem desenvolveremos sua relação com a questão do ambiente e, em particular, do contexto institucional onde operam as empresas. ${ }^{3}$

\section{Inovação, concorrência e recursos}

“... o impulso fundamental que inicia e mantém a máquina capitalista em movimento decorre dos novos bens de consumo, dos novos

\footnotetext{
2 Cuja exploração se encontra ainda em estágio inicial na literatura.

3 Sobre a relação com o contexto institucional, cf., entre outros, Dosi \& Coriat (2002).
} 
métodos de produção ou transporte, dos novos mercados, das novas formas de organização industrial que a empresa capitalista cria ...esse processo de destruição criativa é o fato essencial acerca do capitalismo. É nisso que consiste o capitalismo, e é aí que têm que viver todas as empresas capitalistas" (Schumpeter, 1984:112-3).

Schumpeter publicou estas palavras em 1942. Elas permanecem uma síntese insuperada, e um excelente elo de ligação tanto com desenvolvimentos recentes em estratégia empresarial que abordaremos em seguida, quanto com a perspectiva pós-keynesiana sobre decisões sob incerteza que recuperaremos adiante (cf. seção 3).

Para esses "novos bens de consumo, métodos de produção, etc." Schumpeter reserva o termo inovação. Inovação é, portanto, e como sugere a definição acima, o conceito fundamental da sua análise, e o princípio unificador da sua teoria do desenvolvimento capitalista. ${ }^{4}$

$\mathrm{Na}$ sua teoria, a inovação cuja análise é privilegiada é aquela que representa uma ruptura com o padrão anterior. ${ }^{5}$ Não é mudança na margem, e nem é, em regra, provocada - o que não exclui essa motivação como possibilidade - pela escassez relativa de fatores de produção. As inovações "schumpeterianas" são motivadas pela percepção de oportunidades de mercado transformadas em ganho pelos agentes econômicos (indivíduos ou organizaçôes), mais audaciosos e efetivos. ${ }^{6}$

4 Schumpeter (1976: caps. 2 e 3). Essas definições não são, entretanto, isentas de problemas. A primeira por ser excessivamente restritiva; a segunda, por ser não propriamente uma definição, mas uma taxonomia; e a terceira por ser ambígua demais. Uma forma alternativa, mais sintética, abstrata e precisa de introduzir o conceito de inovação é defini-lo como "a aplicação de novas idéias e métodos na esfera econômica, cujo resultado é a dilatação do 'espaço econômico' existente". Essa definição alternativa é nossa (Burlamaqui, 1995), e não de Schumpeter. Mas é inteiramente compatível com a sua e, acreditamos, mais adequada do ponto de vista teórico, já que é conceitual e abstrata, sem deixar de ser capaz de absorver toda a taxonomia schumpeteriana.

5 Para o setor, ou para a firma, e é fundamental que este ponto seja sublinhado, na medida em que uma inovação incremental para um setor pode ser radical para a história da firma que a introduziu. Por outro lado, e em contraste com a visão do próprio Schumpeter, análises neo-schumpeterianas nas duas últimas décadas têm dedicado muito mais atenção às inovações incrementais do ponto de vista da própria firma, notadamente a partir do reconhecimento do desempenho competitivo das empresas japonesas nos anos 1980, e do início do debate com as teorias em gestão estratégica empresarial.

6 Uma breve observação acerca de uma dimensão "espinhosa" na conceituação de inovação: qual a sua causa? Embora esta pergunta não receba resposta nos escritos de Schumpeter, queremos propor que há boas pistas para ela na sua reflexão. Elas apontam para o fato de que o capitalismo, ao concentrar a energia humana sobre tarefas econômicas, e ao oferecer prêmios significativos para a expansão do espaço econômico existente, cria um meio ambiente extremamente favorável para a aplicação de novas idéias à esfera produtiva (Schumpeter, 1984:100-1). É neste sentido que deve ser entendida a afirmação de Schumpeter de que "as conquistas econômicas da época capitalista devem ser atribuídas 
Inovações têm efeitos múltiplos. Do ponto de vista da empresa inovadora, elas estão na origem de rebaixamentos de custos, de ganhos de produtividade e de qualidade, e, freqüentemente, da monopolização temporária de uma oportunidade de mercado, cujo resultado é a obtenção de lucros extraordinários. Para a estrutura econômica, resultam na criação de novos setores e no rejuvenescimento de setores existentes. Em outras palavras, implicam a reestruturação permanente do espaço econômico existente, através da sua dilatação. Do ponto de vista da concorrência, implicam a criação de assimetrias competitivas, e alteração na configuração das estruturas de mercado. Do ponto de vista do seu impacto macroeconômico, aportam a modificação de agregados e parâmetros do sistema.

Por outro lado, o processo de introdução de inovaçōes não é uma operação trivial. Muito pelo contrário, ele resulta de uma conjugação entre atividade empresarial e condições de financiamento, e está permanentemente diante de dois tipos de barreiras. A representada pela obscuridade do futuro, na medida em que o impacto (sucesso ou fracasso) de uma inovação não tem — por definição - como ser seguramente avaliado ex-ante. E a relacionada com o peso do passado, que está na origem dos hábitos e rotinas empresariais, durabilidade do seu capital fixo e especificidade de seus ativos, todos potencialmente ameaçados pelas inovações.

Esta conjugação entre a incerteza sobre o futuro e o peso do passado está no âmago da complexidade das decisões estratégicas por parte das empresas. E ela se reveste de uma restrição irredutível: a inovação defensável competitivamente é, tipicamente, aquela que mais "carrega passado" — aquela que implica maior nível de comprometimento com uma determinada trajetória, mas que, como contrapartida, pode se revelar mais sensível a mudanças no ambiente. Como veremos logo a seguir, a VBR em estratégia empresarial oferece um quadro conceitual que permite aprofundar esta proposição. ${ }^{7}$

Esta situação implica, por outro lado, que o processo inovativo requer, do ângulo da atividade empresarial, qualidades especiais que, para Schumpeter, em

\footnotetext{
ao sistema capitalista" — incluídos aí seu contexto institucional e sua atmosfera sociocultural —, e não meramente a um progresso técnico independente e exógeno. É também a partir da consideração anterior que propusemos que a pergunta correta a ser feita numa perspectiva schumpeteriana é "por que não surgem inovações num determinado contexto capitalista?", ao contrário da pergunta tradicional sobre por que elas surgem.

7 A associação entre a teoria econômica evolucionária e a VBR veio se conformando ao longo dos anos 1980 e 1990, sendo que uma sinalização academicamente importante, ainda que inicial, foi realizada por Montgomery (1995).
} 
sua primeira versão da teoria (1911), estão objetivadas em indivíduos especiais (os empreendedores); e, em um momento mais maduro (1942), em organizações. Essas qualidades são, basicamente: visão, propensão ao risco, capacidade de tomar decisões em meio a um futuro obscuro, e talento organizacional. Para elas, Schumpeter reserva o conceito de "função empresarial" ou, ainda, empreendedora. ${ }^{8} \mathrm{O}$ ponto que fica na pauta refere-se a como tal "função empreendedora" pode ser observada nas empresas. Novamente, será o caso de buscar vinculações com a VBR, desenvolvidas a seguir.

As raízes da VBR são usualmente atribuídas a Penrose (1959) em sua discussão sobre a natureza e sentido do processo de crescimento da empresa. Essencialmente, a VBR postula que as empresas com estruturas organizacionais e sistemas de coordenação de atividades superiores são lucrativas não por terem uma posição produto-mercado melhor, ou por estarem em um setor mais favorável, mas sim porque se apropriam de rendimentos extraordinários rendas $(\text { rents })^{9}$ — oriundos da escassez, no mercado, de recursos específicos da firma. Ao buscar entender por que estratégias bem-sucedidas não são rapidamente imitadas e então anuladas em sua eficácia, ela assume que são as diferenças em recursos que estão no coração do problema estratégico: recursos singulares são, portanto, "a essência da vantagem competitiva sustentável”.

Neste contexto, as rendas, alvo de qualquer estratégia, fluem de ativos únicos, específicos da firma, que não podem ser imediatamente replicados; são rendas ricardianas. São rendas derivadas da escassez diante da demanda, devidas a fatores valorizados mas inerentemente raros, difíceis de se obter. ${ }^{10}$ A VBR distingue-se, assim, da tradicional discussão de posicionamento inspirada na Economia Industrial (Porter, 1980; 1985; 1996), voltando seu foco de análise para o interior da firma e investigando a força e as deficiências de seu "posicionamento em recursos".

8 A função empresarial ou empreendedora se define em contraposição à gerencial (ou, talvez mais precisamente, operacional). À primeira cabe o papel de criar novas estruturas, à segunda, a de administrar estruturas existentes. Ambas podem (e devem) conviver na mesma organização (ou no mesmo indivíduo) mas diferem conceitualmente.

9 Entendidas na sua acepção ricardiano-marshaliana de quase-rendas de monopólio.

10 A analogia aqui se dá em relação à teoria da renda diferencial (da terra) em Ricardo, onde graus diferenciados de determinadas extensões de terra irão gerar, quando cultivadas, produtos líquidos também diferenciados por conta da irreprodutibilidade, pelas terras de menor fertilidade, do desempenho intrínseco às mais férteis. A VBR trouxe essa analogia para o terreno da organização empresarial através da analogia entre performances diferenciadas entre lotes de terra de fertilidade distinta, e diferenças de performance entre empresas dotadas de recursos com graus de "fertilidade competitiva" também distintos. 
No que concerne à lógica a sustentar a vantagem competitiva, a VBR, portanto, postula, por um lado, assimetrias entre as firmas, na forma de heterogeneidade entre os recursos que cada uma possui. Por outro, que tais recursos singulares terão tão maior valor estratégico quanto mais resistentes sejam em seu valor e singularidade à erosão provocada pela competição — isto é, quanto mais resistentes sejam à imitação e à substituição. ${ }^{11}$

A resistência à imitação é propiciada por "mecanismos de isolamento", tais como especificidade de ativos, aprendizado e experiência acumulados, ambigüidade causal para desempenho excepcional da firma, entre outros (Rumelt, 1984). ${ }^{12}$ A resistência à substituição estará associada ao comportamento da empresa, à sua capacidade de renovar seu posicionamento competitivo. Voltaremos a este ponto logo adiante.

Outras considerações se somam a estas na constituição desta lógica de sustentação da vantagem competitiva. Por um lado, a mobilidade imperfeita dos recursos (no or low-tradeability) é importante para assegurar que as rendas permaneçam sob controle da firma (Dierickx \& Cool, 1989). Neste campo cabem as discussões sobre as ameaças à apropriabilidade, pelos donos na firma, do valor gerado pelo recurso.

Incorporando contribuições de outras abordagens, a VBR discute tal apropriabilidade considerando o risco de oportunismo na co-especialização de ativos e nos investimentos em recursos específicos parcial ou totalmente fora do alcance de propriedade da empresa, ou seja, riscos de captura do valor gerado pelo recurso por outros que não ela. Ela também considera os riscos de folgas (slack) na sua operação, quando a geração de valor real pelo recurso é inferior ao valor potencial por perdas e ineficiências internas à organização (Collis \& Montgomery, 1997; Ghemawat, 1991).

A VBR assume, ainda, que é preciso que as rendas a serem futuramente geradas não sejam sombreadas pelos custos de construção dos recursos singulares que as gerarão (Barney, 1986). A competição por uma determinada posição superior em recursos pode erodir, antes mesmo da competição em si, o valor

\footnotetext{
11 É importante salientar aqui, prevenindo a usual crítica de que a VBR "só olha para dentro", que o valor de um recurso se explica não só pela escassez em si — ameaçada pela imitação — mas também pela demanda sobre aquilo que ele produz — ameaçada pela substituição. Sem que haja demanda, a escassez em si não faz sentido competitivo algum.

12 Este é um dos dois artigos que costumam ser identificados como marco de origem da volta do tema "recursos" à literatura em Estratégia Empresarial. O outro é Wernerfelt (1984).
} 
que este recurso poderia gerar. Os custos para vencer a disputa acabam zerando o saldo final. Neste sentido, a incerteza quanto a futuras fontes de rendas abre campo para constituição de vantagens de first-movers para aqueles que encontrarem o "caminho certo".

As conclusões da VBR incluem, portanto, em um primeiro momento, como fontes de vantagem competitiva, a heterogeneidade e a baixa mobilidade dos recursos, e os limites ex-post (mecanismos de isolamento) e ex-ante (custos de construção inferiores à renda a ser auferida) à competição. ${ }^{13}$

Este conjunto de critérios revela, na gênese da vantagem competitiva, a captura do valor potencial de uma oportunidade por poucos percebida — em suma, uma inovação. Inovação esta conduzida em meio à incerteza, e, portanto, sob riscos de vários tipos. E, na manutenção de tal vantagem, um conjunto de características que a protegem, entre outras, de ameaças de imitação — das perdas relativas à difusão da inovação dentro do seu ambiente concorrencial. Pode-se aqui observar, portanto, como será dito mais de uma vez neste texto, que inovação e estratégia são duas faces de uma mesma moeda.

Se considerada, entretanto, a ameaça de substituição, a própria natureza dos recursos precisa ser esmiuçada, para que se possa melhor compreender a dinâmica envolvida.

Embora seja uma expressão utilizada com razoável liberdade por seus proponentes - por recursos pode-se entender, em termos bem amplos, "qualquer coisa que possa ser pensada como uma força ou uma fraqueza de uma dada firma" (Wernerfelt, 1984) — a utilização instrumental da VBR exigiu uma definição mais precisa do que seriam "recursos".

A proposição central é que um recurso é um atributo da firma que não pode ser alterado no curto prazo. Recursos podem ter várias formas, desde a de fatores de produção comuns até a de ativos altamente diferenciados. Mas devem ser sempre percebidos em seu caráter de estoque, em contraponto às atividades da firma, pelas quais corre o fluxo de receitas, investimentos e despesas (Dierickx \& Cool, 1989).

Pode-se definir os recursos como tangíveis e intangíveis. Os recursos tangíveis, mais fáceis da avaliar, são os ativos visíveis da empresa. Incluem

13 Como bem resumido por Peteraf (1993). 
propriedades, instalaçôes, estoques de matérias-primas, entre outros. Tipicamente, por poderem ser comprados, pouco somam para a vantagem competitiva. Há exceçôes, claro: uma rede de lojas bem instalada e localizada pode representar fonte inestimável de vantagem competitiva sobre concorrentes; a propriedade exclusiva dos direitos sobre uma rica mina de metais preciosos também.

Os recursos intangíveis abrangem os estoques de ativos intangíveis da firma. Inclui atributos tais como marca, cultura, conhecimento tecnológico, patentes, aprendizado e experiência acumulados, entre outros. São ativos com papel normalmente importante, seja para sustentar (ou enfraquecer) posições competitivas ou para valorizar (desvalorizar) a empresa. Além disso, muitas vezes possuem a vantagem de não se deteriorarem/serem consumidos com o tempo. Pelo contrário: seu uso inteligente pode fazê-los mais fortes e mais efetivos.

É deste último ponto, a habilidade da empresa em fazer uso de seus recursos, que se origina um conceito associado a um tipo "especial" de recurso intangível: as capacitações organizacionais da firma.

$\mathrm{Na}$ constatação da importância das capacitações, Penrose (1959:25) já observava que:

"Falando estritamente, não são nunca os recursos [ativos] eles mesmos que são os insumos do processo produtivo, mas apenas os serviços que estes recursos podem render. Os serviços providos por um recurso são uma função da forma como eles são usados — recursos idênticos usados para diferentes propósitos ou de formas distintas ou em combinação com diferentes tipos ou conjuntos de outros recursos, provêem um serviço ou conjunto de serviços diferente. ...recursos podem ser definidos indepentemente de seu uso, enquanto que os serviços, não; a própria palavra serviço implica aí uma atividade, uma função. ...é largamente em função desta diferenciação [no uso dos recursos] que encontramos a fonte da unicidade de cada firma individual."

Os serviços a que Penrose se refere são obtidos dos ativos da firma por um recurso que se caracteriza por não ser um insumo à firma: suas capacitações organizacionais. Estas podem ser definidas como habilidades específicas da organização como um todo ou de suas partes. Nascem de complexas combinaçôes 
de ativos, pessoas, valores culturais e processos operacionais nas organizações. Incluem habilidades de saber fazer a baixo custo (eficiência) e de saber escolher o que fazer (eficácia). Incluem habilidades de fazer avançar o desempenho da organização, seja em termos de novos produtos ou serviços, ou de novos processos de produção, venda, financiamento, divulgação, etc. Capacitações costumam ser, como observava Penrose, atributos-chave na determinação das vantagens competitivas das firmas.

Um ponto interessante é que, embora de mais difícil avaliação do que a de recursos tangíveis, os recursos intangíveis mais definidos, de maior notoriedade e melhor delimitação — efeitos da marca, alcance de patentes — têm sido objeto de melhores estudos quanto ao cálculo de seu valor. Já as capacitações da firma, associadas tipicamente a seus processos de negócio e aos valores que presidem seu padrão (pattern) de atuação, tendem a ser não-consideradas pelos analistas, dada a dificuldade de sua mensuração. Obviamente isto não as torna menos importantes estrategicamente, até pelo contrário: sua típica ambigüidade causal torna-as bem defendidas de imitação pela concorrência.

Os desdobramentos desta assunção da relevância das capacitações, no âmbito do posicionamento em recursos da empresa, abrem campo para um desenvolvimento importante da VBR. ${ }^{14}$

Em sua formulação inicial, o grande mérito da VBR é afirmar a historicidade da firma singular na explicação de seu sucesso presente. Ela reconhece a interligação temporal na função de lucro da firma, de uma forma que, novamente, a análise estratégica ao estilo das oriundas da Economia Industrial, por exemplo, não é capaz de fazer. ${ }^{15}$

A discussão em estratégia empresarial, entretanto, exige mais. Embora a VBR em suas origens considerasse com propriedade o passado na construção da força da posição competitiva presente da firma, e as razões de sua perenidade em um ambiente estável, a questão posta das decisões para o futuro exigia um maior desenvolvimento de seu potencial de avaliação da competição em ambientes assumidos como "dinâmicos". Estes seriam aqueles contextos em que mudanças

\footnotetext{
14 Nosso foco estará no desdobramento da discussão das rendas geradas por capacitações. Não desenvolveremos neste texto a questão das rendas ricardianas de ativos importantes para diversos negócios, tais como localização, patentes, reputação, acesso privilegiado a fontes de matéria-prima, etc., o que, obviamente, não lhes reduz a relevância para economia real.

15 Como assinalado por Ghemawat \& Pisano (1999).
} 
no ambiente, graduais ou súbitas — provocadas pela concorrência, entre outros - atingiriam os pressupostos da estratégia em curso, e colocariam em xeque o valor dos recursos da firma.

A VBR, de fato, sempre esteve aberta a consideraçōes dinâmicas. A própria diferença entre "estoque" e "fluxo", aludida há pouco, implica que as decisões sendo tomadas no "fluxo" de atividades estarão construindo os "estoques" de recursos futuros da empresa. É preciso um padrão consistente, ao longo do tempo, de conformação de recursos, para que se construa um patamar adequado de "estoques" de ativos estratégicos. Uma perspectiva dinâmica sugere, inclusive, que recursos valiosos ajudam a sustentar posições estratégicas fortes; e que ações estratégicas enérgicas ajudam a desenvolver recursos valiosos (Collis \& Montgomery, 1997; Ghemawat \& Pisano, 1999).

Aprofundando tal perspectiva dinâmica, a VBR reforça sua atenção no jogo entre recursos e ações em curso. E retorna, inevitavelmente, à questão da intensidade das dinâmicas de imitação e substituição que permeiam todo o tecido produtivo. Aceitar um "contexto dinâmico" é assumir a dificuldade em resistir a estas dinâmicas. Neste contexto, a força competitiva de uma empresa revela-se menos centrada no "ordenhar" dos recursos acumulados no passado, com seu valor sempre ameaçado, e mais na criação de novos produtos, serviços e capacitaçôes — em inovações.

Em outras palavras, ao assumir o processo concorrencial como schumpeteriano, a VBR incorpora justamente, ao seu núcleo de preocupaçoes, a busca por rendas schumpeterianas, (i.e., baseadas na inovação), a serem conquistadas por inovadores enquanto a difusão bem-sucedida de sua inovação — concretização da ameaça de imitação — não ocorre; ou enquanto um outro inovador não degrada a demanda por sua inovação - concretização da ameaça de substituição.

Com a dinâmica de geração de rendas schumpeterianas em sua agenda, a VBR se volta para a consideração sobre aquelas capacitaçóes particularmente associadas ao processo de inovação. Este conjunto especialmente relevante de capacitações da firma foi nomeado de "capacitações dinâmicas". ${ }^{16}$

\footnotetext{
16 D. Teece, G. Pisano e A. Schuen (1997). A expressão "capacitações dinâmicas", tradução literal da sonora expressão dynamic capabilities, não carrega consigo a imediata identificação com a idéia de habilidades estáveis de gerar inovações. Está em si correta - o adjetivo "dinâmico" quer dizer "o que diz respeito à força, ao movimento" (Dicionário Houaiss et al.) - mas é imprecisa. Uma tradução mais atenta ao significado do conceito proposto seria "capacitações dinamizantes", ou "motrizes", no sentido de serem estas as responsáveis pelo dinamismo da empresa. Mas por força da influência da tradução literal, e dado que ela está em essência correta, assume-se neste texto a tradução "capacitações dinâmicas". Observe-se que os livros publicados no Brasil têm apresentado a tradução "capacidades dinâmicas", o que aumenta a confusão quanto à intenção dos formuladores do conceito, pois o termo "capacidade" se refere tradicionalmente ao volume de produção máximo que uma empresa é capaz de alcançar.
} 
As "capacitações dinâmicas" referem-se às habilidades associadas à inovação dentro da firma. Incluem o desempenho da empresa ao criar e desenvolver novos produtos, processos e rotinas, e responder eficientemente e eficazmente a mudanças ambientais. Tais "capacitaçôes dinâmicas" são, nesse sentido, definidas como críticas para sobrevivência da empresa no longo prazo. São seus "motores de inovação".

Observe-se que não necessariamente uma capacitação dinâmica será uma “capacitação central" (core capability) no âmbito do posicionamento da empresa. As "capacitações centrais" (core capabilities) são aquelas que, gerando resultados pelos quais há demanda, são difíceis de replicar, não podendo ser encontradas no mercado - só podem ser construídas/desenvolvidas - e cujos resultados econômicos são apropriados pela própria empresa (como visto, cumprindo os critérios de geração de valor da VBR).

Uma capacitação dinâmica só será "central” se cumprir esses critérios. Um exemplo aqui pode esclarecer melhor a afirmativa: o caso da Gerência da Qualidade Total (Total Quality Management-TQM) em boa parte dos mercados maduros. Uma boa prática em TQM configura uma capacitação dinâmica importante. Mas, dada sua ampla difusão, ela não é uma capacitação "central".

A hierarquização entre "dinâmicas" e "estáticas" também não deve obscurecer o fato de que, em muitos setores, capacitações estáticas são centrais, estando associadas à sustentação de diferenciais de desempenho em dimensõeschave para competitividade da firma. De nada adiante saber inovar para amanhã se não se consegue sobreviver hoje! Permanece, entretanto, é claro, o fato de que enquanto as "estáticas" são frutos do passado, as "dinâmicas" são as criadoras do futuro.

Ora, como visto, na teoria schumpeteriana, o processo competitivo é percebido como o motor do desenvolvimento capitalista, e as inovações como seu combustível. A evolução é percebida como...

“...uma história de revoluções ...Um processo de mutação industrial que incessantemente revoluciona a estrutura econômica a partir de dentro, incessantemente destruindo a velha, incessantemente criando uma nova. É nisso que consiste o capitalismo, e é aí que têm que viver todas as empresas capitalistas. ...todos os elementos da estratégia empresarial só 
adquirem sua verdadeira significação contra o pano de fundo desse processo, e dentro da situação por ele criada. Devem ser vistos sob o vento perene da destruição criadora” (Schumpeter, 1984:112-13).

Nessa conhecida passagem é possível reconhecer, justamente, os fundamentos de uma conexão dinâmica entre inovações, estratégias empresariais e reconfiguração de estruturas de mercado. Trata-se de um processo permanente de reestruturação porque propelido ininterruptamente por todos os tipos de inovação (radicais, incrementais, de produto, processo, organização, gestão, marketing, etc.). Um olhar schumpeteriano concebe a competição como um processo disruptivo - e não como ajustamento - cujo resultado é a monopolização temporária de oportunidades de mercado e a conseqüente diferenciação - e não equalização — das taxas de lucro ( i.e., com geração de renda para os "diferenciados").

A noção schumpeteriana de concorrência potencial oferece uma interessante conseqüência da conexão dinâmica entre estratégias, inovações e reconfiguração ambiental: o fluxo permanente de novos produtos e métodos de produção e organização concorrem com os velhos em condições de superioridade, o que pode significar a "morte" para os últimos; para evitar a destruição, todas as empresas são obrigadas — mais ou menos rapidamente a seguir o exemplo, e investir.

Isto, por sua vez, implica a percepção da concorrência como o condicionante básico das estratégias empresariais, e, simultaneamente, do seu impacto transversal sobre a estrutura econômica no presente e para o futuro. Ou seja, o processo competitivo opera não só em mercados existentes e entre empresas do mesmo setor, mas também entre empresas de setores diferentes, e por mercados que só existirão de fato no futuro, embora suas raízes estejam plantadas no presente, por intermédio de suas políticas de pesquisa e desenvolvimento.

A idéia central é de que as inovações, tanto radicais quanto incrementais, estão permanentemente destruindo e reconstruindo barreiras à entrada e à imitação, tornando-as mais permeáveis ao longo do tempo. Há, portanto, uma relação de feedback entre as estratégias inovativas das empresas e as estruturas de mercado resultantes, no contexto da concorrência enquanto "destruição criadora". 
A concorrência surge, pois, como uma "usina de diferenciação", uma poderosa alavanca de promoção de eficiência produtiva — e de introdução de incerteza - agindo, no tempo, de modo a expandir e diversificar a produção, e reduzir custos e preços. Nessas condições, mesmo "uma posição de monopólio não é um travesseiro sobre o qual seja possível repousar" (Schumpeter,1984:135).

Ao assumir a concorrência schumpeteriana como referência, uma análise nos termos da VBR destacará o alcance e a centralidade das capacitações dinâmicas da firma. Estas constituem, agregadas, a função empreendedora da firma, no sentido que Schumpeter deu ao termo. O processo de construção do posicionamento em recursos terá de ser considerado ao longo do tempo passado, presente e futuro. Sua habilidade de gerar um futuro superior - de inovar na direção correta - será, no longo prazo, o aspecto crítico de sua sobrevivência e prosperidade.

Neste sentido, a Gestão Estratégica apoiada na VBR assume que o sistema capitalista é inerentemente dinâmico e potencialmente instável, justamente em função da presença da concorrência entre as empresas e dos processos de inovação que estas se vêem obrigadas a conduzir. Para ela, o monopólio não é o contrário da concorrência; é, como visto, o resultado temporário do processo competitivo. Ela buscará, nos resultados da prática de suas capacitações dinâmicas, construir uma base de recursos que lhe permita alcançar posiçóes monopolistas, para receber o prêmio representado pelos lucros extraordinários inerentes a tal tipo de posição.

Em suma, sobrelucros são conseqüência da construção de vantagens competitivas; e sua sustentação depende de recursos singulares de difícil imitação, entre os quais se destacam capacitações estáticas e dinâmicas — estas últimas como instrumentos para a necessária reafirmação constante de sua superioridade competitiva. $\mathrm{Na}$ ausência de tais atributos à empresa, a posição monopolística tende a ser temporária, porque a própria dinâmica competitiva a ameaça, seja através das inovações de outras empresas, seja por intermédio da imitação criativa inerente aos processos de difusão de inovaçôes. Novamente, é possível observar que inovação e estratégia se mostram lados distintos de uma mesma moeda.

Tem-se, assim, uma perspectiva evolucionária da empresa, onde o tempo e o timing da ação cumprem papel importante na definição de vencedores e perdedores. Abre-se campo para que se considere um segundo aspecto relevante na caracterização da dinâmica competitiva capitalista: a discussão sobre o processo 
de tomada de decisões sob incerteza, tal como se origina na obra de Keynes, bem como suas implicações do ponto de vista da dinâmica estratégica da empresa. Esta é tratada como o dilema do "comprometimento estratégico" pela VBR, elemento fundamental para explicar a diferença de performances entre empresas ao longo do tempo.

\section{Decisões empresariais sob incerteza e comprometimento estratégico}

No prefácio à Teoria Geral, Keynes fixa um ponto de partida para a sua teoria do funcionamento do capitalismo, o qual se materializa no conceito de economia monetária:

"Uma economia monetária, iremos ver, é essencialmente uma economia em que mudanças de pontos de vista sobre o futuro são capazes de influenciar o volume de emprego e não meramente a sua direção" (Keynes,1983:4).

A interpretação pós-keynesiana das idéias de Keynes privilegia justamente esse ponto de partida, e o utiliza para construir uma perspectiva teórica radicalmente distinta elaborada pelo mainstream na análise sobre como operam as economias capitalistas. É possível sintetizá-la partindo de três pressupostos:
a) agentes dotados de poder de escolha;
b) tempo econômico (irreversível e expectacional);
c) incerteza.

As implicações teóricas desses três pressupostos são profundas e significativas, como veremos, bem como a sua convergência com a perspectiva evolucionária. Há evidente complementaridade entre a "teoria geral das decisões empresariais sob incerteza" contida na obra de Keynes, e a "teoria geral dos fatores propulsores da dinâmica capitalista", coluna vertebral da reflexão schumpeteriana e da teoria econômica Evolucionária em geral. Vejamos por que.

Quanto ao primeiro pressuposto, a presença de agentes econômicos com poder de escolha, mas também submetidos às dificuldades da escolha, significa 
que eles são criativos e, simultaneamente, conscientes de que podem errar. ${ }^{17}$ Poder de escolha se traduz, do ponto de vista das decisóes empresariais, em diversidade comportamental, ou multiplicidade de estratégias. Dito de outra forma: os agentes econômicos são criativos na sua interação com o meio ambiente que os cerca. Isso se traduz, do ponto de vista das implicações conceituais, em dois resultados:

i) os contextos onde os agentes que decidem não se repetem, na medida em que o padrão de interação entre as decisões muda continuamente (os contextos são não-ergódigos, nas palavras de Davidson,1982);

ii) o futuro não é cognoscível no presente, pois é construído por agentes criativos, porém ignorantes das açôes dos demais e, portanto, do impacto das suas próprias ações no tempo — na medida em que tal impacto só se revela quando da sua interpenetração com as outras ações. Ou seja, agentes criativos implicam vários futuros possíveis, ou, de forma mais direta, sua imprevisibilidade: o futuro só pode ser conhecido quando ele se tornou passado ... (cf. Shackle, 1972).

É justamente a partir do anterior que se abre o espaço próprio para a inserção do segundo pressuposto, e condicionante fundamental de uma economia monetária de produção: o conceito de tempo. A definição de tempo econômico como unidirecional — irreversível portanto — implica a consideração da mudança como uma conseqüência também da influência do passado (vivido) e do futuro (imaginado) sobre as decisões tomadas no presente, o que obriga encará-la como um processo contínuo e unidirecional de destruição e reconstrução de situações, sobredeterminado por duas dimensões simultâneas, porém distintas:

a) a influência do passado sobre o futuro dada pela "memória" do sistema econômico; isto é, pelo peso das decisóes tomadas no passado, consubstanciado nas estruturas econômica, social, e institucional existentes - contextos e processos alimentados por convençóes, estruturas de passivo, especificidade

\footnotetext{
17 Não desenvolveremos aqui a questão dos limites da racionalidade empresarial no mundo real — por exemplo, a questão da racionalidade limitada do agente, e de seu horizonte restrito a uma solução satisfatória e não ótima, tal como formulado por H. Simon. Sobre o tema, cf. Burlamaqui (1995) e Possas (2002).
} 
de ativos e durabilidade do capital fixo - "pontes viscosas" entre o presente e o futuro. Em uma palavra: irreversibilidade;

b) a influência do futuro sobre o presente através das avaliações (expectativas) formadas pelos agentes, no momento das suas decisões: tempo expectacional (Shackle, 1972; Carvalho, 1983-84).

$\mathrm{O}$ anterior suscita uma importante questão: por que o futuro tem tanta importância sobre as decisões tomadas no presente? A resposta de Keynes é conhecida: porque grande parte das nossas ações presentes está voltada para, ou orientada pelo, futuro. Envolvem decisões cujo impacto não é imediato; e, no caso das empresas, implicam a expectativa de obtenção de receitas líquidas, e de compromissos financeiros futuros.

Isso por sua vez, cria espaço para o conceito, cunhado por Shackle (1972), de decisóes cruciais. As decisões empresariais são cruciais tanto por suas causas, quanto por suas conseqüências. Do ponto de vista da causalidade, porque os agentes sabem que podem errar e, que se o fizerem, incorrerão necessariamente em perdas, podendo, no limite, "quebrar". As decisões são cruciais também pelas suas consequiências: elas destroem o contexto onde foram tomadas, criando irreversibilidades, descontinuidades, e possibilidade de futuros alternativos.

A decisão de investir é uma decisão crucial por excelência, dada sua "causa" - o conhecimento que seria necessário para sua correta avaliação simplesmente não existe no momento de sua decisão - e por suas conseqüências — porque muda o contexto de onde se originou. ${ }^{18}$ Em poucas palavras: investir é se tornar ilíquido, sem a garantia quer de recuperar a liquidez, quer de valorizar o capital investido. A contrapartida é que investir pode significar a criação de uma fonte de lucros extraordinários (i.e., rendas ricardianas e schumpeterianas) no futuro.

Diante das influências do passado sobre as ações possíveis no presente, e do futuro sobre as decisões correntes, e dada a ignorância incontornável a seu respeito, torna-se imperativa a introdução do terceiro pressuposto acima referido: a incerteza surge como elemento indissociável da ação econômica, e as expectativas por ela condicionadas como o filtro através do qual a conexão entre presente e futuro é avaliada. Ambos — incerteza e expectativas — são,

\footnotetext{
18 Como Keynes argumenta "o nosso conhecimento dos fatores que regularão a renda de um investimento alguns anos mais tarde é, em geral, muito limitado e, com freqüência, desprezível" (Keynes, 1973:125).
} 
portanto, elementos constitutivos da racionalidade dos agentes econômicos e da construção de estratégias empresariais.

Observe-se que sob esta perspectiva teórica, investir exige arrojo e determinação: os animal-spirits de que falava Keynes. Esse "espírito vital” é análogo ao componente subjetivo da função empreendedora schumpeteriana.

Em Gestão Estratégica, a questão crítica das decisões cruciais, e de suas conseqüências para o futuro, foi desenvolvida, no âmbito da VBR, destacando o que Ghemawat (1991) chamou de "comprometimento (commitment) estratégico".

Basicamente, o comprometimento estaria associado à decisão de assumir investimentos significativos no desenvolvimento de um conjunto específico de recursos. Usualmente, tais "poucas decisões de grande porte" são irreversíveis por seu alcance e extensão, que mudam o perfil dos recursos utilizados pela firma. São elas que definem o futuro da empresa, e onde a incerteza inerente ao futuro na competição capitalista se mostra com toda sua força. São as decisões que enfrentam o drama da aposta em um determinado futuro, frente a todos os outros possíveis. São decisões "estratégicas" justamente por definirem as restrições e o potencial de evolução da firma no longo prazo. São decisóes cruciais, no sentido que Shackle deu ao termo.

Ou seja, as decisões de elevado comprometimento estratégico implicam seguir determinado leque possível de trajetórias, e abandonar definitivamente outros percursos. Implicam apostar em determinadas possibilidades para determinados prazos, e assumir as consequiências dos importantes efeitos culturais e políticos que terão na organização. Podem implicar a destruição de valor gerado pela situação presente de recursos. Podem conter em seu acerto ou erro a possibilidade da empresa sobreviver ou não às mudanças ambientais. E estão na gênese do fenômeno de "dependência em relação à trajetória" (path dependence).

Vistos por esse ângulo, os três pressupostos da formulação pós-keynesiana, e suas consequiências, se articulam harmonicamente à formulação original de Ghemawat e lhe sublinham a importância. Inserida no contexto da VBR, a discussão sobre as relações entre tempo econômico, incerteza e decisões cruciais contribui para consolidar a compreensão da dinâmica estratégica empresarial. Tanto pela plena incorporação do passado como trajetória de decisões aplicadas, refletidas num "estoque" dado de ativos; quanto pela assunção do futuro como irremediavelmente obscuro. Esta situação impõe às decisões (estratégicas) 
tomadas no presente uma complexidade da qual gerentes e CEOs (Chief Executive Officers) não podem se libertar. ${ }^{19}$

A assunção da existência de comprometimento estratégico — repita-se, de contenção das possibilidades futuras dentro de um leque restrito de opções dadas pelas decisões passadas - pela VBR alcança também a compreensão do papel estratégico das capacitações dinâmicas.

Uma primeira constatação é que a própria direção de construção das capacitaçōes da empresa constitui-se em uma decisão de elevado comprometimento. As capacitaçōes organizacionais se "acumulam" ao longo do tempo, formandose incrementalmente. Dá trabalho desenvolvê-las. É preciso um esforço gerencial coordenado e inteligente para fazê-lo. E, como espelho de qualquer conjunto de capacitações centrais, encontramos "elementos de rigidez" ou "inabilidades" igualmente "centrais" (Leonard-Barton, 1992). A saber, desempenhos que a empresa não tem como alcançar simplesmente porque se desenvolveu em outra direção. É aquilo que ela, enquanto organização, não sabe e não tem como fazer acontecer.

Este desenvolvimento pode se dar com maior ou menor sucesso. A capacidade de fazê-lo bem — uma capacitação dinâmica de melhoria — é uma capacitação relevante em si. Uma simples diferença de valor nos gastos entre duas empresas para o desenvolvimento de uma capacitação " $x$ ” não explicará as diferenças nos resultados alcançados pelas organizaçōes — a forma pela qual este investimento é concretizado pode ser mais ou menos produtiva.

Por outro lado, há que considerar a capacidade da empresa em reformular seu posicionamento, e a lógica e direção de desenvolvimento de suas capacitaçóes (e, concomitantemente, de acúmulo de recursos em geral). Essas habilidades, um tipo particular de capacitação dinâmica, podem ser chamadas de "capacitaçôes evolucionárias" (Fujimoto, 1998). Tais capacitações são associadas à habilidade de desenvolver novas capacitações estáticas e de melhoria. Elas estão no âmago do que se pode denominar de "flexibilidade estratégica" — a habilidade da firma em reposicionar-se no ambiente, à medida em que este evolui.

A relevância de destacar analiticamente um novo subconjunto, as capacitações evolucionárias, está, justamente, em ressaltar que, como entidades

\footnotetext{
19 Sua inserção contribui, em particular, para elucidar de modo preciso a conclusão de Ghemawat de que "... a irreversibilidade implícita no comprometimento exige um olhar profundo e cuidadoso em relação ao futuro" (1991:29).
} 
vivas que são, as empresas, se sofrem comprometimentos de variados tipos, também podem se "recriar". Seja pela criação de novos negócios, seja pela combinação dos recursos que possuem com aquilo que as ameaças de substituição possam lhe oferecer, entre outras alternativas. Em suma: "dependência de percurso" não é sinônimo de obrigação de destino.

Cabe observar que, ao apontar a necessidade, para teoria econômica, de formular sua análise desde o ponto de vista do agente, de se colocar "na sua pele", e tentar decifrar que comportamentos ele adota frente a situações que não conhece, Keynes introduziu uma inovação metodológica importante. Tal demanda aponta para o fato de que a teoria econômica deve entender melhor como se comporta concretamente este agente. Neste sentido, há um último elo complementar importante para nossa síntese conceitual: uma formulação consistente sobre como se formam, na prática, as estratégias empresariais.

\section{O processo estratégico e a visão baseada em recursos}

O processo concreto de formação das estratégias empresariais vêm sendo objeto de estudo das pesquisas em Gestão Estratégica já há quase 30 anos (cf. p.ex. Mintzberg, 1973; 1978). Num certo sentido, o que se procurava inicialmente era avaliar o quanto os processos formais de Planejamento Estratégico, então em voga nas empresas, contribuíam, de fato, para uma maior efetividade das mesmas em seus mercados.

Os resultados apontaram, de forma crescente e consistente, que as empresas, organizações vivas e em relação constante com seu ambiente, têm, na verdade, suas estratégias formadas ao longo de processos complexos e multidimensionais, informados não só pelo seu componente formal - o procedimento burocrático definido para consecução do planejamento da empresa - mas também, e muitas vezes principalmente, pelas dinâmicas políticas, culturais e cognitivas vividas pelos seus membros, presentes nas relações com os diversos agentes em seu entorno, e associadas às características de seu ambiente de operação. ${ }^{20}$ Novas estratégias formam-se freqüentemente pelo acúmulo de decisões cotidianas sobre que prioridades assumir, ou sobre como conduzir no detalhe suas operações.

\footnotetext{
20 Há uma vasta literatura no tema. Cf., entre outros, Mintzberg \& Quinn (1996) e Mintzberg et al. (1998).
} 
Este processo de formação de estratégias, simplificadamente referido como "processo estratégico" na literatura, encontrou uma representação simples, mas instrutiva, reproduzida na Figura 1.

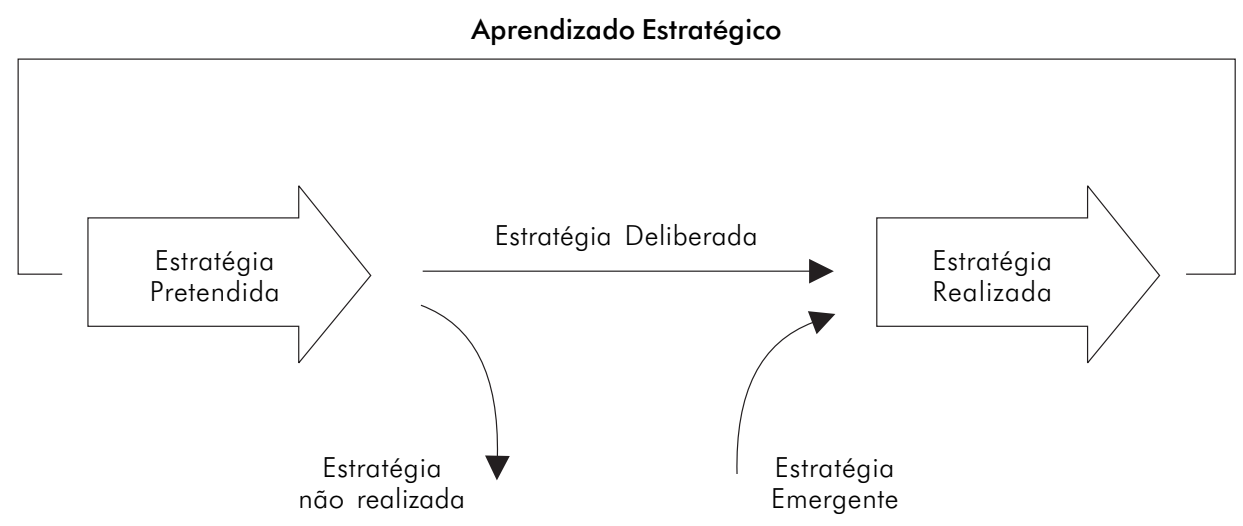

Figura 1: O processo estratégico (Mintzberg \& Waters, 1985)

Na Figura 1, o que é denominado a "estratégia realizada" é a estratégia que é. É aquilo que a empresa realmente faz, não aquilo que ela diz que faz, ou o que a Direção pretendia fazer. Neste sentido, pode-se assumir a definição de "estratégia" não como um "plano" ou o "posicionamento competitivo" almejado (i.e., calculado), mas sim como "um padrão (pattern) em um fluxo de ações" (Mintzberg \& Waters, 1985).

A figura ressalta que tal estratégia efetivamente realizada pela empresa é produto tanto de um componente deliberado, estabelecido na origem do processo de conformação da estratégia, provavelmente pela Direção da empresa; como de um componente emergente, gestado dentro da própria organização ou imposto pelo ambiente, ou ambos, que substitui parte do que se pretendia, que fracassou (não se realizou). Tal componente emergente não deve ser associado a imagens de caos ou confusão. Ele é uma ordenação não-intencionada das ações, que se combina com os efeitos das intenções iniciais para formar o padrão (pattern) final que caracteriza a estratégia da empresa.

A figura também destaca que o processo de formação de uma estratégia se dá em ciclos (repetidos) de renovação, marcados pelo ali denominado "aprendizado estratégico". Este aprendizado é coletivo: a organização observando o que realmente fez e, tendo processado cognitivamente esta experiência, 
redefinindo suas pretensões. Pois se a estratégia se define por um padrão coletivo de ação, é preciso que ela tenha seu sentido esclarecido para cada membro da organização (particularmente os envolvidos com tomadas de decisão) desde o ponto de vista de seu contexto particular.

Tal esquema conceitual sugere pesos relativos distintos para os componentes deliberado e emergente das estratégias empresariais diante de diferentes situações de mercado. Em mercados novos em rápido crescimento, ou sob grande turbulência, é provável que o componente emergente seja dominante. A Direção pode procurar "domesticar" este processo de emersão estabelecendo balizas para a atuação criativa de seus tomadores de decisão definindo limites para o negócio da empresa, ou regras para a configuração de novos produtos, por exemplo. Mas, basicamente, o que a situação exige é que não se percam oportunidades, e que se aprenda mais sobre o ambiente e sobre a melhor forma de lidar com ele.

Uma vez que um padrão de sucesso esteja configurado - como reflexo, tipicamente, do fato de o regime de funcionamento do ambiente estar estabilizado, i.e. com suas lógicas mercadológicas, econômicas, sociais, etc. estabelecidas — a Direção pode buscar explicitar, em sua estratégia pretendida, normas, procedimentos e políticas que cuidem de assegurar a coerência entre as açóes de todos, de forma a sustentar o bom posicionamento (enfim) alcançado. Se tiver entendido bem a natureza de seu sucesso, é provável que sua iniciativa seja bem acolhida pela organização, usualmente em busca de redução da ansiedade inerente ao lidar com a incerteza. Tal situação dará um forte peso relativo ao componente deliberado da estratégia.

Ambas situações evidenciam, novamente, a idéia de que estratégia e inovação são dois lados da mesma moeda. Se no primeiro caso a força do componente emergente revela o momento da criação do novo e do inédito, o segundo fala da ordenação da inovação como forma de reafirmar um dado posicionamento competitivo vitorioso.

Associar esta representação às proposições da VBR é pertinente, justamente por mostrar a coerência entre uma tal visão do "processo estratégico" com o "conteúdo estratégico" objeto da VBR. O que se pode ler na primeira etapa do ciclo é o processo de acumulação de recursos. Seja pela aquisição de algum ativo fixo, seja pelo desenvolvimento de uma tecnologia, ou pelo fortalecimento da 
marca de uma linha de produtos, seja pelo amadurecimento de alguma capacitação.

Em particular, o desenvolvimento de capacitações guarda evidentes componentes deliberados e emergentes. A ação coletiva inerente a este recurso implica sua origem em uma prática constante, passível de aprendizado e aperfeiçoamento endógeno. Na verdade, ao final de uma "rodada" do processo estratégico, é provável que a empresa disponha de um leque de capacitações previstas e não-previstas, assim como se ressinta da ausência de capacitações almejadas e não-alcançadas (Proença, 1995). O que fará então — sua nova pretensão — estará condicionado pelo novo ambiente em que se encontra, e por aquilo em que realmente se tornou.

Este será o momento de evidenciar o quilate de suas capacitações evolucionárias - como visto, sua capacidade de definir e desenvolver novas capacitaçóes, o que equivale a dizer redirecionar seu posicionamento competitivo - diante da realidade ambiente/firma em que se encontra.

Esta segunda parte do ciclo — a do "aprendizado estratégico" na figura — será tanto mais difícil quanto a Direção estiver mais comprometida com uma determinada "visão de empresa". ${ }^{21}$

O processo de tunelamento ao qual uma empresa pode se ver submetida nesta trajetória está magnificamente descrito por Christensen (1997), na forma do "dilema do inovador". Basicamente, o que Christensen evidencia é que as melhores práticas gerenciais modernas tendem a associar fortemente todas as atividades da cadeia de valor da empresa bem-sucedida ao atendimento de seus principais mercados, com o melhor que seus produtos podem ser. Sua estratégia será acumular recursos - em particular, capacitações — em uma mesma direção - na direção de desempenhos superiores ao longo deste vetor "projeto/ produção/venda/satisfação do cliente".

Diante, entretanto, do que Christensen nomeou "inovações disruptoras" (disruptive innovations) — inovações que rompem a lógica de atendimento a uma determinada necessidade, implicando uma reconformação de produtos, processo, e mercados — ${ }^{22}$ a efetividade deste vetor desaba. Os seus mercados deixam de sê-lo, seus segmentos se desfazem e perdem identidade; seus produtos

\footnotetext{
21 A ser tomada como uma paráfrase do conceito de cosmovisão (weltanschauung) da Filosofia.

22 Na definição schumpeteriana, são as chamadas "inovações radicais destruidoras de competências".
} 
tornam-se obsoletos, "cheios de excessos inúteis" (overdeveloped); e suas capacitações duramente desenvolvidas passam a soar ridículas, irrelevantes. $\mathrm{O}$ dilema do inovador aparece quando fica claro que, ao inovar, uma firma pode, justamente, soprar o vento da "destruição criadora" na direção mesma dos pilares que sustentam sua existência e seu sucesso.

Um tal dilema teria algumas alternativas de solução: no âmbito da mesma Corporação, criar uma nova unidade de negócio, centrada na inovação disruptora em curso; ou, levar a Corporação para outros pontos da cadeia de suprimento, que se vejam valorizados pela inovação em curso; ou, buscar investir nos novos negócios já em curso fora da Corporação; ou, o que é mais relevante para a temática deste artigo, reorientar a organização em direção a um novo posicionamento competitivo que tenha por base seu histórico de acumulação de ativos e capacitações.

Esta última situação é aquela em que a própria unidade de negócio, ou seu equivalente, a firma singular, se vê às voltas com a instabilidade crônica da concorrência capitalista.

Observe-se que o desafio em pauta para esta unidade de negócio não é de pouca monta. A prática gerencial moderna foca no desenvolvimento daquelas capacitaçôes que atendam à demanda, que sejam de baixa imitabilidade, e que gerem situações de poder de barganha para a empresa. Essas "capacitações centrais" têm como reflexo "rigidezes centrais", como anteriormente observado. Ao vivenciar intensa e repetidamente os processos tal como sedimentados pelo seu sucesso - inclusive estabelecendo importantes capacitações de melhoria — a empresa não aprende, e mesmo "desaprende", outras formas de agir.

Pois, como já dito, desenvolver capacitações centrais também implica "comprometimento estratégico". E se trata de um comprometimento inevitável, pois a ele está associada a própria construção de uma posição singularmente bem-sucedida e defensável. Não parece haver saída, portanto, no âmbito da firma ou unidade singular, senão esperar a inovação disruptora que decretará seu fim.

Ao assumir a empresa como uma organização viva e potencialmente capaz de aprender também "novos truques", entretanto, a questão se desloca para esfera gerencial. O desafio está em desenvolver modelos de gestão que superem o tunelamento provocado pelas práticas de gestão modernas, permitindo que 
uma mesma empresa possa construtivamente migrar para novas posições bem sucedidas. Trata-se, portanto, de desenvolver capacitaçôes evolucionárias na firma — objetivo último do que poderíamos denominar de Modelos de Gestão contemporâneos.

Nos termos da discussão acerca de decisôes sob incerteza, isto se traduz em um Modelo de Gestão que preconize formas de atuação que assegurem uma maior "liquidez estratégica", aqui no caso referida não ao perfil de ativos mas a uma determinada forma de gestão estratégica. Ou seja , em um Modelo de Gestão que tenha por premissa a necessidade de ser competitivo em uma determinada posição, em um determinado momento, pela constituição de uma base específica de recursos; mas que procure assegurar a capacidade da organização migrar, a baixo custo, para outras formas de entender e operar sua relação com o mercado e a concorrência.

O conceito de "liquidez estratégica" é, portanto, análogo ao da "preferência pela liquidez" keynesiana. A flexibilidade estratégica que lhe é implícita é, entretanto, mitigada pela necessidade irredutível de comprometimento estratégico. Isto é, mesmo a empresa que busca liquidez estratégica se defrontará com a irreversibilidade associada aos seus investimentos em ativos e capacitações.

Assumindo que o processo estratégico tem componentes deliberados e emergentes, e que o que se busca, em síntese, são Modelos de Gestão que permitam às empresas refinar suas capacitações evolucionárias, redefine-se a própria idéia de Modelo de Gestão: de uma solução para implementar uma estratégia, ${ }^{23}$ para uma solução que ordene e acelere o andamento do processo estratégico. Ou seja, que permita maior e mais rápido aprendizado estratégico. ${ }^{24}$

Um Modelo de Gestão dará solução a questões de diversas ordens políticas, sociais, culturais, econômicas, afetivas. Os vínculos entre seu potencial

\footnotetext{
23 No famoso adágio de Chandler (1962), "a estrutura segue a estratégia".

${ }^{24}$ Neste sentido, pode-se assumir que Modelo de Gestão é "o conjunto de premissas e orientações que preside o desdobrar em processos específicos, em estruturas de administração (alcances de controle, direitos de decisão, alcances de informação) e de gerência de recursos humanos (papéis gerenciais, relacionamentos, estrutura de incentivos), e em orientações para o comportamento gerencial (valores), da lógica da dinâmica de processo estratégico almejada" (Proença et al., 2001). De fato, do ponto de vista schumpeteriano, a empresa é, essencialmente, um agente de transformação. E dadas as características da competição, a organização de uma empresa é uma estrutura administrativa basicamente criada para gerar estratégias, com hierarquias coordenando o trabalho dividido. Neste sentido, este "novo" Modelo de Gestão está perfeitamente adequado às premissas evolucionárias acerca do funcionamento concreto das economias capitalistas. Vale observar que o conteúdo deste Modelo está em plena discussão, até por estar em formação. Sugestões interessantes podem ser encontradas, entre outros, em Quinn (1992) e Bartlett \& Ghoshal (1997), como descrição e prescrição; e em Sennett (2000), sob críticas e demanda por alternativas.
} 
de sucesso e o quadro institucional, societal e cultural onde a empresa se insere são evidentes.

Um bom exemplo de proposta associada a esta opção por "liquidez estratégica" está na proposição de Eisenhardt \& Sull (2001). Sua formulação de "estratégia como regras simples" para mercados de "alta velocidade" — onde a única coisa constante é a mudança — ${ }^{25}$ preconiza, justamente, que, para crescer consistentemente em uma ambiente de elevada incerteza e muitas oportunidades, as empresas devem centrar-se em alguns processos chave (i.e., em um punhado de capacitações centrais) e em regras simples e difundidas entre os gestores quanto à tomada de decisão diante das oportunidades emergentes no ambiente.

Seus casos de referência - Yahoo!, Miramax, Lego, Cisco, entre outros - lhes permitem estabelecer uma tipologia de tais regras, e alguma orientação quanto à reprodução desta abordagem em outros ambientes. Eles sugerem, portanto, a nosso juízo, como seria um comportamento adequado diante de algumas situações de necessária predominância do componente emergente de seus padrões de atuação.

\section{Conclusão: em direção a uma teoria estratégica da firma}

Recuperando os aspectos centrais da síntese conceitual aqui proposta, temos, em primeiro lugar, que o ambiente econômico característico da concorrência schumpeteriana é também, como o proposto por Keynes, nãoergódigo. No seu interior, a decisão de inovar é específica da firma, e absolutamente estratégica. Se for verdade que a recriação/expansão de lucros permitida pela inovação é a contrapartida do seu impacto sobre a eficiência (produtividade, qualidade e diferenciação) do processo onde está sendo introduzida, e mais ainda, sobre a competitividade do agente que a introduz, também é fato que a construção e sustentação dessa mesma competitividade requer tempo. Ou seja, não se materializa em um incremento rápido de retornos esperados. A dimensão estratégica da inovação nasce, em um primeiro momento, justamente do seu impacto esperado sobre a manutenção da capacidade de competir da empresa; é a sua mola mestra.

25 Na famosa expressão de Michael Dell. 
Por outro lado, a cumulatividade associada às decisões relativas à formação de seu estoque de ativos e de habilidades específicas criam irreversibilidades. Tal comprometimento estratégico, contrapartida da decisão de inovar, sugere, por sua vez, uma ponte conceitual explícita entre a concorrência via inovações, a acumulação de recursos e a assunção de comprometimentos: inovações criam e reconfiguram a base de recursos, através de decisões que implicam comprometimentos estratégicos.

O corolário do anterior é que a decisão de inovar (e em que inovar) é uma decisão crucial, no sentido de que destrói as condições — os parâmetros - que balizavam seu ponto de partida: cria assimetrias, modifica convenções, implica riscos, e está associada a incertezas de diversas naturezas (ambientais, de desenvolvimento de produto, quanto a ameaças competitivas, condições de financiamento, etc.) de modo que, sua "calculabilidade" econômica tende a ser sempre um processo complexo e cercado de imprevisibilidades.

Essa proposição implica uma segunda conexão: a natureza da decisão de inovar é, como a decisão de investir em Keynes, necessariamente especulativa. É uma aposta, que depende das expectativas dos empresários sobre o futuro, as quais se formam a partir de suas avaliações — parte objetivas, parte subjetivas - acerca do potencial de cada alternativa (inclusive, a de nada fazer). Sua sistematização requer um ambiente macroeconômico e institucional que permita um mínimo de previsibilidade econômica e confiança em relação ao futuro e, ainda assim, exige animal-spirits por parte das empresas, para impulsionar seu distanciamento do comportamento convencional.

A dimensão de incerteza inexorável associada à decisão de inovar, o fato de que ela pode vir a originar fontes cumulativas de lucros e incrementos de competitividade, mas que simultaneamente implica riscos substantivos, é o que explica a busca de "liquidez estratégica" - que pode se manifestar tanto no escopo potencial dos resultados associados aos recursos acumulados, como na decisão de investir em capacitaçôes dinâmicas de melhoria e evolucionárias, que permitam à empresa reforçar ou rever sua forma de atuação e inserção no tecido econômico.

Dessa perspectiva, portanto, a abordagem pelas capacitações dinâmicas é uma clara evolução relativamente à por "recursos historicamente acumulados". Ela realça o papel crucial dos Modelos de Gestão das empresas, e evidencia que 
a forma como a empresa conduz o próprio processo de formação de estratégias é, em si, um ativo intangivel especifico central.

Trata-se, na linguagem do modelo conceitual proposto neste artigo, de oferecer, como horizonte de desempenho, que a empresa seja capaz de promover a criação de habilidades e conhecimentos coletivos como elemento central de sua estratégia competitiva, articulando o gerenciamento de inovações à criação de diferenciação organizacional, e amortecendo os inevitáveis elementos de rigidez (commitments) associados às decisões cruciais. Este é o sentido da idéia de buscar "liquidez estratégica”. Isto é, desenvolver estratégias e formas de gestão estratégica que permitam modificar, adaptar, reestruturar e, no limite, reverter e reinventar a empresa.

Tal formulação só é possível com a consideração de uma Teoria Estratégica da Firma. Isto é, um entendimento da empresa como agente de transformação do tecido econômico que, em meio à incerteza, decide acumular determinado leque de recursos e capacitações ao longo do tempo, sob pena de não resistir ao processo de destruição criadora. Esta empresa materializa-se em uma organização viva, onde processos deliberados e emergentes ganham forma, no contexto da solução de gestão adotada.

Esta teoria deve assegurar, em sua conformação, a articulação entre concorrência, inovação, competitividade, incerteza, comprometimento e busca de liquidez estratégica. Este encaminhamento, para a qual o presente artigo se pretende uma modesta contribuição, será um "microfundamento" essencial para uma reconstrução não ortodoxa da Teoria do Desenvolvimento Econômico. ${ }^{26}$

\footnotetext{
26 Isto é, de uma Teoria do Desenvolvimento Econômico que tenha no centro do seu arcabouço conceitual os mercados como um tipo especial de instituição; a concorrência como um processo seletivo que introjete no sistema, simultaneamente, progresso e conflito; a empresa como estrutura organizacional projetada para coordenar recursos, administrar incertezas e voltada para a criação de conhecimento e capacitações dinâmicas; e a centralidade da política pública para estabilizar e regular a dinâmica de sistemas econômicos estruturalmente instáveis. Nesse sentido, ver Minsky (1996), Nelson (1996), e as contribuições recentes de Potts (2000), Teece (2000), Fligstein (2001), Baumol (2002), Possas (2002) e Kregel \& Burlamaqui (2003).
} 


\section{Bibliografia}

Barney, J. B., "Strategic factor markets: Expectation, luck and business strategy”, in Management Science, v. 32, p. 1231-1241, 1986.

Baumol, W., The Free-Market Innovation Machine. Princeton University Press, 2000.

Burlamaqui, L., "Capitalismo Organizado no Japão, uma interpretação a partir de Schumpeter, Keynes e Polanyi”. Tese de Doutoramento, IE/UFRJ, 1995.

; Proença, A., "Decisões sob Incerteza, Concorrência e Estratégias: uma proposta de síntese conceitual”. In Arché Interdisciplinar, Rio de Janeiro, v. 15, 1997.

, "Evolutionary Economics, Strategic Mangement and Uncertainty: A Commitment-Capabilities Approach”. Trabalho apresentado na Eigth (Millenium) Conference: Change, Development and Transformation: Scumpeterian Perspectives. International J. A. Schumpeter Society. Manchester: 2000.

Carvalho, F., "On the Concept of Time in Schacklean and Sraffian Economics", in Jounal of Post Keynesian Economics, inverno, 1983/4.

Chandler, A., Strategy and Structure, Cambridge, MA: MIT Press, 1962.

Christensen, C. M., The Innovator's Dilemma, New York: Harper Collins, 1997.

; Overdorf, M., "Meeting the Challenge of Disruptive Change", in Harvard Business Review, mar.-abr., p. 66-76, 2000.

Collis, D. E.; Montgomery, C., Corporate Strategy: Resources and the Scope of the Firm, Chicago: Irwin, 1997.

Davidson, P., Money and the Real World, Londres: MacMillan, 1984.

Dierickx, I. E.; Cool, K., "Asset stock accumulation and sustainability of competitive advantage", in Management Science, v. 35, n. 12, p. 1504-1514, 1989.

Dosi, G.; Coriat, B., "Problem-Solving and Coordination-Governance: Advances in a Competecnce-Based Perspective on The Theories of The Firm", in Revista Brasileira de Inovação, v. 1, n. 1, jan./jun., 2002.

Eisenhardt, K. M.; Sull, D. N., “Strategy as Simple Rules”, in Harvard Business Review, jan., p. 106-119, 2001.

Fligstein, N., “The Architecture of Markets”, Princeton: Princeton University Press, 2002.

Foss, N. (org.), Resources, Firms and Strategies. New York: Oxford University Press, 1997.

Fujimoto, T., "Reinterpreting the Resource-Capability View of the Firm: a Case of DevelopmentProduction Systems of the Japanese Auto-Makers" in Chandler Jr., A. D.; Hasgström, P.; Sölvell, Ö., The Dynamic Firm. Oxford: Oxford University Press, 1998. 
Ghemawat, P., “Commitment: The Dynamic of Strategy”, in The Free Press, New York: 1991. , Strategy and the Business Landscape. Reading, MA: Addison-Wesley, 1999. ; Pisano, G., "Building and Sustaining Success", in Ghemawat, P.; Strategy and the Business Landscape, Addison-Wesley, Reading, MA, 1999.

Ghoshal, S.; Bartlett, C. A., The Individualized Corporation, New York: Harper Business, 1997. Kregel, J. A.; Burlamaqui, L., "Innovation, Organizational Capabilities and Finance - A Theoretical Contribution for Rethinking Development", in De Paula, S.; Dymski, G. A. (orgs.) Reimagining Growth. E. Elgar (no prelo), 2003.

Leonard-Barton, D., "Core Capabilities and Core Rigidities: A Paradox in Managing new Product Development” in Strategic Management Journal, v. 13, p. 111-125, 1992.

Loasby, B., Equilibrium and Evolution. U.K.: Manchester University Press, 1991.

Magnusson, L. (org.), Evolutionary and Neo-Schumpeterian Approaches to Economics, Kluwer Press, 1994.

Minsky, H., "Uncertainty and The Institutional Structure of Capitalist Economies”, Jerome Levy Institute, Ensaio para trabalho, n. 155,1996.

Mintzberg, H.; Ahlstrand, B. E.; Lampel, J., Strategic Safari: a guided tour through the wilds of strategic management, New York: The Free Press, 1998.

, "Strategy-Making in Three Modes", in California Management Review, v. 16, n. 2, p. 44-53, inverno, 1973.

, "Patterns in Strategy Formation", in Management Science, v. 24, n. 9, maio, 1978.

; Quinn, J.B. (orgs.), The Strategy Process: Concepts, Contexts, Cases, Prentice-Hall International, $3^{\text {a }}$ ed., London, 1996.

; Waters, J. A., "Of Strategies, Deliberate and Emergent", in Strategic Management Journal, v. 6, p. 257-272, 1985.

Montgomery, C. (org.), Resource-Based and Evolutionary Theories of the Firm - Towards a Synthesis. Kluwer Press, 1995.

Nelson, R.; Winter, S., An Evolutionary Theory of Economic Change, Cambridge: Harvard University Press, 1982.

, The Sources of Economic Growth, Cambridge, Mass.: Harvard University Press, 1996.

Penrose, E., The Theory of the Growth of the Firm, $3^{\mathrm{a}}$ ed, New York: Oxford University Press, 1995. Ed. original em 1959.

Peteraf, M. , "The Cornerstones of Competitive Advantage: A Resource-Based View”, in Strategic Management Journal, v.14, p.179-88, 1993. 
Porter, M., "What is Strategy?", in Porter, M., On Competition, Cambridge: Harvard Business School Press, 1998. $1^{\text {a }}$ ed., Harvard Business Review, nov./dez., 1996.

, Competitive Advantage, New York: The Free Press, 1985.

, Competitive Strategy: Techniques for Analyzing Industries and Competitors, New York: The Free Press, 1980.

Possas, M.L., "Elementos para uma integração Micro-macroeconômica na Teoria do Desenvolvimento Econômico", in Revista Brasileira de Inovação, v. 1, n. 1, jan./jun., 2002.

Potts, J., The New Evolutionary Microeconomics - Complexity, Competence and Adaptative Behaviour, Cheltenham: Edward Elgar, 2000.

Proença, A.; Caulliraux, H.; Cameira, R.; Business Strategy and Management Models: A Contemporary Approach. Salvador: VII ICIE; 2001.

, "Estratégia Competitiva e Estratégia de Produção: uma Introdução Esquemática”, in Caulliraux, H.; Costa, L. S. S. (orgs.), Manufatura Integrada por Computador, Rio de Janeiro: Editora Campus, 1995.

Quinn, J. B., Intelligent Enterprise. New York: John Wiley \& Sons, 1992.

Rumelt, R. P.; Schendel, D. E.; Teece, D. J. (orgs.), Fundamental Issues in Strategy, Cambridge, MA: Harvard Business Scholl Press, 1995.

Schumpeter, J., Capitalismo, Socialismo e Democracia, Rio de Janeiro: Jorge Zahar Editor, 1984. , "Towards a strategic theory of the firm", in Lamb, R.B. (org.), Competitive Strategic Management, Englewood Cliffs, NJ: Prentice Hall, 1984.

Sennett, R., Corrosão do Caráter. Rio de Janeiro: Editora Record, 2000.

Shackle, G., Epistemics and Economics, Transaction Books, 1992, ed. orig. em 1972.

Teece, D., Managing Intellectual Capital. Oxford: Oxford University Press, 2000.

; Pisano, G.; Schuen, A., "Dynamic Capabilities and Strategic Management”, in Foss, N. (org.), Resources, Firms and Strategies, Oxford: Oxford University Press, 1997.

Wernerfelt, B., "A Resource-Based View of the Firm”, in Strategic Management Journal, v. 5, p.171-180, 1984. 